\title{
Scare tactics
}

$\mathrm{M}$ r. Jones was known on the ward as the cancer patient with the lopsided smile. Chemotherapy had "messed him up," according to his wife.

"Don't you see? Half his face is gone. It's like he only has one cheek left."

Mrs. Jones had been dubious of their oncologist's plan from the beginning. A survivor of stage III breast cancer, her relationship with the medical system had always been conflicted; the treatments that had eradicated the cancer from her breast had also left her with permanent, painful disabilities. Although thankful to be alive, she had never been able to forgive her physician for the adverse effects of treatment. Now, as Mrs. Jones watched her husband suffer through round after round of chemotherapy, she felt a resurgence of mistrust.

Mr. Jones, on the other hand, remained in good spirits. He greeted me every morning in the same way.

"Hello, young doctor. Are you going to diagnose me with another problem today?"

Unlike his wife, whose skepticism was real, he was playful. I had grown fond of our daily bedside banter, and we bonded quickly, despite the scowling presence of his wife.

One morning, instead of welcoming me with his usual smile, he shared a grievance.

"My right leg feels weak."

It was a simple enough complaint, and I had no reason to react with concern. Here in the chronic care ward, the patients lay bed-bound and weak. Many of them were too deconditioned to lift a hand, an arm - or, for that matter, a leg.

"How long has it lasted?" I asked.

"About three hours. Ever since I woke up this morning, I haven't been able to lift the darned thing."

"Ok, let me examine you."

I asked him to raise his left leg, which he did easily. But when I asked him to do the same with the right, he could hardly move it. Curious. I

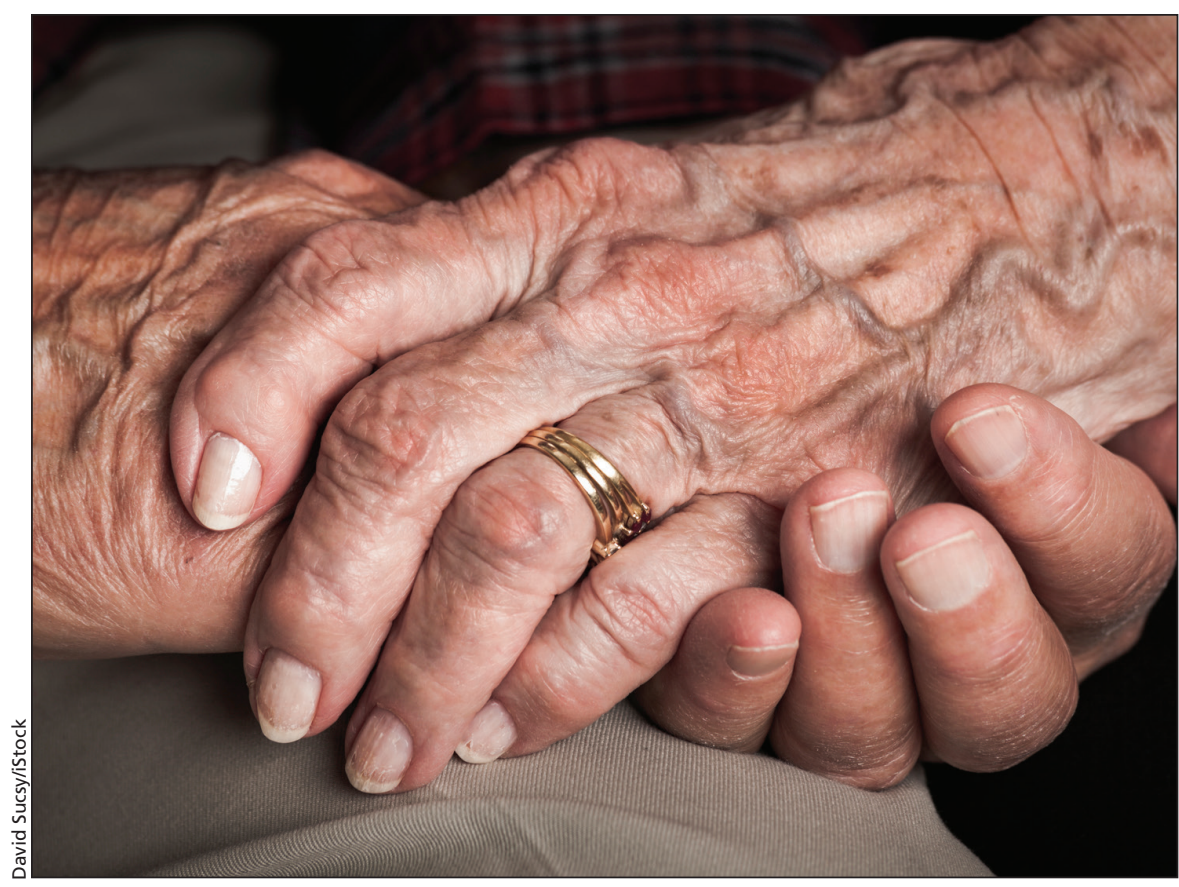

tapped his right Achilles tendon with the end of my stethoscope. Instead of the quiver I was expecting, his whole foot lurched up, as if I had touched him with something hot. That's strange. I scratched his right heel with my finger, and immediately his big toe shot up toward the ceiling. Oh, shit.

"Ow! What was that for?"

I mentally ran through the handful of diagnostic possibilities suggested by my exam. None of them looked good. Acute cerebral infarction. Metastatic cancer with spinal cord compression.

"Mr. Jones," I said, trying to keep my voice calm, "I'm worried by what I see. I think we need to investigate your weakness right away with a CT [computerized tomography] scan."

"Wait just a minute!" cried Mrs. Jones, jumping out of her seat. She had been watching me all along with suspicion. "We've been through this too many times before, so please don't expect us to play along."

"I understand ...".

"No, you don't understand!" she cried. "It always begins with a tiny worry. Then come the unnecessary tests, and the results are completely normal. Isn't that right, Jim?"

I should have known that appeals to Mrs. Jones' reason would succeed only in delaying the CT scan upon which so much depended. With every minute, our ability to undo the damage from Mr. Jones' stroke - if that is, in fact, what he was experiencing - grew less promising. Irreparable brain injury was probably occurring as we spoke.

"Listen," I said, turning to Mrs. Jones. "If we don't do the CT scan right away, your husband could die."

I had blurted the words out in a final crude effort to circumvent Mrs. Jones' stubbornness, and I knew they had done the trick, even before I saw the panic setting in her eyes. Without a word, she resumed her place in the seat and took her husband's hand.

"Are ... are you sure?"

I couldn't be sure what Mr. Jones' symptoms portended, let alone when he might die. Yet, in that moment, I could think of no faster way to obtain his wife's consent than to invoke her ultimate fears.

Scare tactics are never easy to justify, especially when your own under- 
standing of the clinical situation is murky at best. But what was the alternative? Should I have passed up the opportunity to investigate my concerns and allowed Mr. Jones to suffer the consequences of inaction?

"No, I'm not sure. That's why we need to do the scan," I said.

Fear of losing Mr. Jones had compelled my use of the scare tactic; now, the same fear was compelling Mrs. Jones to reconsider her original decision. She must hate me, I thought to myself. As a student physician, I belonged to the very system she both resented and mistrusted, and she was loathe to place her faith in me. But I had left her with no choice.
"Ok, you have my permission."

In the rush of activity that ensued, I did not have time to think about whether I had done the right thing. I filled out an urgent $\mathrm{CT}$ requisition and handed it to the ward clerk, who faxed it to the imaging department. Only later, as I watched the porters wheel Mr. Jones away, did I begin to wonder. If the CT scan was normal, I might cause Mrs. Jones to lose what little faith she still had in the medical system. And yet, if the scan showed a stroke - something we could treat if we acted quickly — I might restore some of that lost trust. The trouble was that I couldn't be sure how the situation would unfold. What if my tactic
- which was meant for good - had done serious, irreparable harm?

In the growing silence, I asked myself whether I had just widened, or bridged, the chasm between Mrs. Jones and the system I represented.

\section{Shaurya Taran MD BSc}

Internal Medicine, University of Toronto, Toronto, Ont.

This article has been peer reviewed.

This is a true story, but details have been changed to protect the identity of the patient and his wife.

CMAJ 2016. DOI:10.1503/cmaj.160306 